\title{
MUSEU DE CIÊNCIAS MORFOLÓGICAS DA UFG COMO INSTRUMENTO FACILITADOR NO PROCESSO ENSINO-APRENDIZAGEM
}

\author{
Phâmella Neres de Lima; Matheus Santos Costa; João Marcelo \\ Nogueira de Rezende; Geovanna Pires de Almeida; Ana Cristina \\ Silva Rebelo; Paulo César Moreira; João Roberto da Mata; Edson \\ José Benetti; Karina Simões; Paulinne Junqueira Silva Andresen \\ Strini; Nilza Nascimento Guimarães; Augusto César Ribeiro \\ Figueiredo; Fabiana Ribeiro da Mata
}

Resumo: O Museu de Ciências Morfológicas da Universidade Federal de Goiás (MM-UFG), contém um amplo acervo de peças anatômicas humanas e animais e tem propiciado a divulgação do conhecimento científico. Foi avaliado o papel do MM-UFG como instrumento facilitador no processo ensino-aprendizagem no estudo anatômico do corpo humano e animal. Os dados foram coletados durante as visitas de estudantes do ensino fundamental e médio de março a agosto de 2017. Foram recebidos 713 visitantes de escolas públicas e privadas, graduandos da UFG e de outras instituições de ensino superior e cursos técnicos. Houve um grande número de estudantes atendidos com intensa participação revelando a importância educativa do acervo museológico no estudo do corpo humano e animal. Concluiuse que o Museu de Morfologia da UFG possui um importante papel no processo ensino-aprendizagem e na divulgação científica do conhecimento.

Palavras-chave: Ensino-aprendizagem. Anatomia. Divulgação Científica. Museu de Morfologia da UFG

UFG MUSEUM OF MORPHOLOGICAL SCIENCES AS A FACILITATOR INSTRUMENT IN THE TEACHING-LEARNING PROCESS

Abstract: The Museum of Morphological Sciences of the Federal University of Goiás (MM-UFG), contains a large collection of anatomical human and animal parts and has promoted the dissemination of scientific knowledge. The role of the MM-UFG as 
a facilitator in the teaching-learning process was evaluated in the anatomical study of the human and animal body. Data were collected during the visits of elementary and middle school students from March to August 2017. 713 visitors were received from public and private schools, graduates of UFG and other higher education institutions and technical courses. There were a large number of students attended with intense participation revealing the educational importance of the museological collection in the study of the human and animal body. It was concluded that the Museum of Morphology of the UFG has an important role in the teaching-learning process and in the scientific dissemination of knowledge.

Keywords: Teaching-learning. Anatomy. Scientific divulgation. Museum of Morphology of UFG

\section{MUSEO DE CIENCIAS MORFOLÓGICAS DE LA UFG COMO INSTRU- MENTO FACILITADOR EN EL PROCESO ENSEÑANZA-APRENDIZAJE}

Resumen: El Museo de Ciencias Morfológicas de la Universidad Federal de Goiás (MM-UFG), contiene un amplio acervo de piezas anatómicas humanas y animales y ha propiciado la divulgación del conocimiento científico. Se evaluó el papel del MMUFG como instrumento facilitador en el proceso enseñanza-aprendizaje en el estudio anatómico del cuerpo humano y animal. Los datos fueron recolectados durante las visitas de estudiantes de la escuela primaria y media de marzo a agosto de 2017. Se recibieron 713 visitantes de escuelas públicas y privadas, graduados de la UFG y de otras instituciones de enseñanza superior y cursos técnicos. Hubo un gran número de estudiantes atendidos con intensa participación revelando la importancia educativa del acervo museológico en el estudio del cuerpo humano y animal. Se concluyó que el Museo de Morfología de la UFG posee un importante papel en el proceso enseñanzaaprendizaje y en la divulgación científica del conocimiento.

Palabras clave: Enseñanza-aprendizaje. Anatomía. Divulgación Científica. Museo de Morfología de la UFG

\section{INTRODUÇÃO}

Durante muito tempo pensava-se que a educação poderia ser aplicada apenas dentro de instituições meramente formalizadas, tendo o professor como o único praticante do ensino. Porém ao longo dos anos, assim como a sociedade alavancava na busca pela quebra de vários paradigmas, o entendimento do 
que seria a educação começava a ter outras configurações, que antes haviam sido discutidos por filósofos, sociólogos, historiadores e até pedagogos.

Para uma melhor definição do que é educação baseamos no Antropólogo Carlos Brandão que, em sua obra O que é educação, publicada em 1981 expressou um pensamento do que poderia ser a educação:

\footnotetext{
Ninguém escapa da educação. Em casa, na rua, na igreja ou na escola, de um modo ou de muitos todos nós envolvemos pedaços da vida com ela: para aprender, para ensinar, para aprender-e-ensinar. Para saber, para fazer, para ser ou para conviver, todos os dias misturamos a vida com a educação. Com uma ou com várias: Educação? Educações. (BRANDÃO, 1981, p. 3)
}

Nessa perspectiva a educação é intrínseca ao ser humano. Enquanto seres racionais vivemos e produzimos saberes a todo momento em todo lugar, sempre partindo de uma vivencia, experiência ou conhecimento prévio acerca daquilo que é estudado pelo sujeito. Essa ideia de poder experimentar a educação através de vários vieses torna-a plurifacetada e descentraliza o pensamento de que ela tem endereço fixo e um único mediador. Não desmoralizamos o ensino escolar e nem a prática do profissional professor, mas queremos dar ao leitor a ideia de que educar pode ser um processo feito em todo lugar. Pois, segundo Carlos Brandão "Não há uma forma única nem um único modelo de educação; a escola não é o único lugar onde ela acontece e talvez nem seja o melhor; o ensino escolar não é a sua única prática e o professor profissional não é o seu único praticante." (1981, p.4)

Logo para se disseminar e internalizar o saber, é necessária uma ação pedagógica bem estruturada, baseada nas convicções políticas de cada grupo social. Sendo esta praticada por agentes educativos formais e não-formais, ocorrendo em não apenas na família, na escola, mas também nos meios de comunicação, nos movimentos sociais e outros grupos humanos organizados e instituições não escolares. (LIBÂNEO, 2012, p. 27).

Por conseguinte, nos deparamos com vários lugares que podem servir como espaços educativos. A partir daí a educação praticada nesses lugares podem ser compreendidas como formal, informal e não formal. Resumidamente, a educação formal, possui uma característica de ser intencionalizada, sistematizada, estruturada, organizada e institucionalizada. Por outro lado, a educação informal, é conhecida por ser um modelo não institucionalizado, não intencionalizada e 
nem organizada, mas que advém das relações que o sujeito possui com amigos, familiares e o meio em que ele vive, de forma natural e espontânea.

A educação não-formal possui um certo grau de organização e intencionalidade fora da sistematização, entretanto ela não está fundamentada em uma instituição escolar. Ou seja, ela busca objetivar nos sujeitos uma forma de assimilação daqueles saberes abordados em outros locais propícios para o aprendizado. O que contribui e proporciona uma aprendizagem de conteúdos da escolarização formal (VIERA et al., 2005 p. 21).

Os Museus são ambientes que proporcionam a comunicação, educação e difusão cultural para um público amplo e diversificado (VALENTE, et al., 2005). Pois nesse tipo de espaço, podem ser encontrados uma equipe técni$\mathrm{ca}$, bem como acervos compostos de diversos materiais e que conduzem o visitante ao conhecimento sobre vários assuntos, desde a pré-história até os tempos atuais. Assim, os museus se mostram ambientes benéficos e capazes de fornecer saberes relacionados a diversos assuntos.

Nesse sentido o Museu Comunitário de Ciências Morfológicas Arlindo Coelho de Souza da Universidade Federal de Goiás (MM-UFG), tem buscado oportunizar aos seus visitantes momentos de aprendizagem através da interação destes com o acervo museológico disponível e com a ação de educadores engajados no ato de difundir o conhecimento (FERREIRA et al., 1997; De SOUZA et al., 2001). Afim de contribuir com a formação dos monitores, as visitas são assistidas por eles, que também realizam palestras e apresentam o bioacervo do museu, interagindo com o público e dando subsídios para o despertamento da curiosidade dos visitantes sobre as peças anatômicas do ambiente.

A melhoria no conhecimento do público visitante do MM serve como base para o aperfeiçoamento do planejamento das atividades futuras. Ademais, é notório que ao exercer a ação de ensinar também está em construção o efetivo desenvolvimento da docência, e as informações obtidas servirão para se fazer as opções mais adequadas no sentido de promover e conduzir o processo da aprendizagem (ROLDAO, 2007).

As atividades desenvolvidas no MM-UFG visam contribuir e incentivar o crescimento de uma nova consciência sobre saúde, cidadania e compromisso com qualidade de vida. Os estudos sobre o público, assim como a avaliação das exposições dos museus, apontam para o imperativo de considerar o visitante como um participante ativo. Por outro lado, ao buscar o conhecimento do público visitante se amplia as possibilidades de aproveitamento da 
aprendizagem. Isto ocorre porque, na maioria das vezes, os visitantes trazem na sua bagagem questionamentos e atitudes que são determinantes na riqueza da experiência do aprendizado (STUDART, 2005; ALMEIDA, 2005).

Aberto a visitas semanais, o MM-UFG tem atendido a diversas instituições bem como projetos desenvolvidos pela UFG tais como: "A Comunidade vai á UFG", "Conhecendo a UFG" e o "Espaço das Profissões (EP)", oferecidos anualmente. Atentando-se ao público-alvo o impasse de se formar cidadãos humanizados e éticos se confronta com a cultura tecnológica ao passo em que são disseminados comportamentos éticos, como por exemplo, o respeito ao cadáver. Segundo o artigo 212 do código penal brasileiro, o desrespeito ao póstumo é um crime de vilipêndio, no qual abrangem também as peças anatômicas, uma vez que as mesmas são de pessoas que possuíam uma personalidade, uma vivência e experiências. Neste sentido, a conscientização da comunidade acerca do exposto é de suma importância, assim como a propagação de ideais preservacionistas tanto ambientais quanto científicas, visando construir uma concepção ética acerca dos cadáveres expostos.

O trabalho com a extensão no MM-UFG tem propiciado aos professores o entendimento de que a extensão, inquestionavelmente deve ser uma prática acadêmica interdisciplinar com uma gestão preferencialmente colegiada objetivando sempre buscar e promover parcerias (PROEC, 1997a). As ações de extensão praticada no MM- UFG têm sido pensadas a médio e longo prazo, para que estas atividades não sejam apenas mais uma microutopia, mas que busque o papel efetivo de agente promotor da educação e cidadania. $O$ trabalho em busca da disseminação do conhecimento do MM- UFG tem promovido melhorias na compreensão do autoconhecimento e autocuidado dos indivíduos atendidos, a partir da visão dinâmica do corpo humano e dos animais. Os visitantes ampliaram seus horizontes a partir das informações sobre as formas e funções do seu próprio corpo, o que contribuiu na construção da sua identidade.

Sendo possível o uso de interdisciplinaridade, muitas vezes tendo partido dos próprios visitantes por dúvidas ou comparações que vão além dos conteúdos anatômicos e morfológicos, como citado acima, para melhor compreensão do processo de interdisciplinaridade:

"A interdisciplinaridade não dilui as disciplinas, ao contrário, mantém sua individualidade. Mas integra as disciplinas a partir da compreensão das múltiplas causas ou fatores que intervêm sobre a realidade e trabalha sobre as linguagens necessárias para a constituição 
do conhecimento, comunicação e negociação de significados e registro sistemático de resultados". (DCN, 1999, 133)

O MM-UFG tem atuado com importância no processo de ensino-aprendizagem, na tentativa de relacionar os conteúdos didáticos, estipulados pelas diretrizes curriculares de ensino, que muitas vezes são considerados absurdamente distintos. Desta forma, o MM-UFG tem se revelado como uma ferramenta metodológica lúdica na difusão do conhecimento científico para estudos e pesquisas, possibilitando a integralização e a inclusão da sociedade no universo do saber ao complementar o trabalho das escolas (SABATTINI, 2003 apud LOZADA, 2006). Conhecer o ser humano como produto do conhecimento é substancial, ao passo em que se podem atingir diversas esferas do âmbito coletivo. Esta abrangência se contrasta com a falta de visibilidade da relação "Universidade-Escola” (LEÃO et al., 2015).

Buscando afirmar seu importante papel formador no processo de aprendizagem, baseado em várias concepções já apresentadas, o museu buscou analisar o perfil dos visitantes durante um espaço de tempo amostral, reforçando sua função e objetivação dentro do âmbito institucional e regional.

\section{Овjetivos}

Este estudo avaliou o papel do Museu de Ciências Morfológicas da UFG como instrumento facilitador no processo ensino-aprendizagem e sua contribuição na promoção e ampliação do conhecimento sobre os vários órgãos e sistemas constituintes do corpo humano e animal para discentes do ensino fundamental, médio e de graduação. Analisou também o perfil do público visitante ao MM-UFG para melhorar a divulgação alcance ao maior número de instituições.

\section{MATERIAIS E MÉTODOS}

Os dados foram obtidos de estudantes do ensino médio e de graduação de instituições públicas e particular que foram recebidos para a visita ao Museu de Ciências Morfológicas da UFG durante todo o ano de 2017, também, buscando analisar, de maneira breve, se houve percentual de aumento de visitas 
agendadas ao MM-UFG, foram comparados os valores totais dos anos de 2015, 2016 e 2017.

Quando as instituições chegavam na UFG, eram direcionadas à um espaço físico onde foi ministrada uma palestra sobre o estudo anatômico do corpo humano e animal, a utilização do cadáver para o estudo científico e o papel do MM-UFG no estudo de anatomia. Enfatizou-se também a ética e a importância do estudo no cadáver humano e animal. Nesse momento de palestra os visitantes tiveram a oportunidade para sanar suas dúvidas e curiosidades. Em seguida, os discentes foram conduzidos até o espaço físico do MM-UFG onde além da presença de um docente as visitas contavam com o auxílio de monitores capacitados a responder dúvidas. $\mathrm{O}$ estudo dos órgãos e sistemas foi realizado em peças anatômicas previamente dissecadas e fixadas em exposição no $\mathrm{Mu}$ seu de Ciências Morfológicas da UFG. As informações sobre as instituições de ensino de origem dos visitantes foram obtidas a partir da coleta dos livros Ata (de preenchimento obrigatório durante a visita), e ofícios ao Departamento de Morfologia da UFG. Estes dados foram contabilizados e analisados.

\section{RESUlTADOS E DISCUSSÃO}

O MM-UFG desde sua criação na década de 70 tem se destacado pela grande quantidade de visitantes que recebe anualmente. Constituídos principalmente por discentes do ensino médio e fundamental, cujas escolas não possuem um laboratório de ciências que possibilite o estudo prático do corpo humano e animal, é perceptível a curiosidade desses indivíduos acerca das estruturas morfológicas. O grande número de estudantes da educação básica, pública ou privada, que foram atendidos, reforça o importante papel MM-UFG na construção e ampliação do conhecimento. Partindo dessa compreensão, o estudo sobre o perfil do público visitante possibilita a melhoria na divulgação das atividades do MM-UFG, o que objetiva alcançar o maior número de escolas bem como o direcionamento do estudo anatômico para atender as necessidades de conhecimento e compreensão durante o estudo do corpo humano e animal.

O MM possui um acervo rico em peças anatômicas humana e animal. Os estagiários anualmente fazem um catálogo de todas as peças identificando nome, origem e quando possível a data de recebimento. O espaço físico possui uma ambientação em 3 (três) salas. A primeira sala contendo esqueletos de 
animais de grande porte: um boi, um bisão, um camelo e dois cavalos, além de uma vértebra de baleia que é colocada próxima à duas vertebras de cachorro para que os visitantes tenham noção da diferença no tamanho entre mamíferos. Nesta sala a maioria dos estudantes demonstraram interesse em conhecer mais sobre cada esqueleto, ficando surpresos com o tamanho dos ossos desses animais, como a vértebra da baleia e a estrutura corporal do camelo, pois muitos deles achavam que as duas corcovas desse animal eram formadas somente por ossos, quando na verdade uma é formada pelo acúmulo de gordura e a outra pelos processos espinhosos das vertebras torácicas.

Na segunda sala há uma maior quantidade de peças, sendo: uma pele de Onça Parda taxidermizada, um Cachorro taxidermizado, um Jacaré-Açu taxidermizado, um Tamanduá Bandeira taxidermizado, um Galo Taxidermizado, uma Jaguatirica taxidermizada, um ovo de Avestruz, um ovo de Ema, um par de patas de Avestruz, um crânio de Javali, um crânio de Capivara, um crânio de Bode, um crânio de Porco, um esqueleto completo de Papagaio, um esqueleto completo de Periquito Australiano, um esqueleto completo de Perdiz Portuguesa, um esqueleto completo de Galinha, um esqueleto completo de Pombo, um esqueleto completo de ave não identificada, um esqueleto completo de Tiêtinga, um esqueleto completo de Numbu Quaçu, um esqueleto de Gavião Carijó, um esqueleto completo de Urubu, um esqueleto completo de Marreco, um esqueleto completo de Lobo Guará, um esqueleto completo de Macaco Guariba, um esqueleto completo de Onça Preta/Pantera Negra, um esqueleto completo de Tatu Canastra, um esqueleto completo de Tatu Meleta (Meletinha), um esqueleto completo de Quati, um esqueleto completo de Ema, um esqueleto completo de Corujão das Torres, um esqueleto completo de Anta, um esqueleto completo de Ariranha, um esqueleto completo de Pato, um esqueleto completo de Garça, um esqueleto completo de Cachorro de raça Poodle, um esqueleto completo de Cachorro de raça Fila, um esqueleto completo de Cachorro vira-lata, um esqueleto completo de Cisne, um esqueleto completo de Porco de Granja, um esqueleto completo de Vaca, um esqueleto completo de Gato, um esqueleto completo de Cavalo, um esqueleto completo de filhote de Leão, um esqueleto completo de Chimpanzé, um esqueleto completo de filhote de Camelo, um esqueleto completo de Camelo, dois esqueletos completos de Lhama, dois esqueletos completos de Rato, dois esqueletos completos de Macaco Prego e três esqueletos completos de Bode. 
Ainda nesta sala criamos um ambiente mais próximo possível ao habitat dos animais presentes, utilizando areia, pedaços de tronco, pedras e plantas artificiais e folhas secas. Neste ambiente repleto de esqueletos de animais, possui também um esqueleto humano sobre um cavalo, na tentativa de deixar o ambiente a ser relacionado com o realismo ou até mesmo de modo comparativo entre os animais, alguns esqueletos foram montados de forma artística, como o esqueleto completo de um Chimpanzé subindo e um tronco de arvore; um esqueleto completo de Papagaio e um esqueleto completo de Periquito Australiano foram montados lado a lado para comparação de tamanho. A oportunidade de conhecer de perto cada particularidade dos esqueletos de diversos animais despertou a curiosidade e o interesse da maioria dos estudantes atendido, uma vez que nesta sala, boa parte do bioacervo apresentado não possui espécies de vida livre na fauna americano, como exemplo o Leão, Chimpanzé, Girafa e Hipopótamo.

Durante a passagem na segunda sala muitas questões foram levantadas entre os alunos e muitas dúvidas direcionadas aos monitores, professores e acompanhantes. O Jacaré-Açu é a peça de maior destaque nesse ambiente, devido ao questionamento dos visitantes se a peça se trata de um Jacaré ou Crocodilo, é dado um tempo para que os visitantes analisem e pensem a qual família pertence o animal, antes do término da passagem na sala dois é explicado as diferenças mais visíveis entre jacarés e crocodilos: os dentes de crocodilo são alinhados com os dentes inferiores, o que não ocorre nos jacarés, os crocodilos possuem o quarto dente maxilar inferior, hipertrofiado, quando sua boca está fechada, esse dente fica exposto, já nos jacarés os dentes possuem tamanho padronizado e a exposição demasiada do quarto dente, como o dos crocodilos, não ocorre. Após essas explicações os alunos conseguem analisar a peça e identifica-la como um Jacaré, sendo esse um momento importante no processo de ensino-aprendizagem.

A terceira sala foi o ambiente mais procurado, os alunos demonstram bastante curiosidade sobre as possíveis peças que souberam que estão presentes no MM-UFG, e também o ambiente que os visitantes normalmente mais demoram durante a visita. São muitas as dúvidas que existem pois, é neste espaço que temos o acervo humano para exposição além de peças que possuem variações anatômicas e anomalias tanto humanas quanto animal. As peças estão alocadas em uma determinada sequência: no início da sala há uma bancada expondo peças anatômicas completas de fetos humanos em diferentes 
estágios de gestão, estão expostas em sequência cronológica do desenvolvimento, contanto com uma peça anatômica completa de feto humana envolto de um útero, para melhor compreensão anatômica de uma gestação humana, por fator de curiosidade há um útero normal e um útero com cisto, o que causa muitas dúvidas e espanto entre os visitantes; em sequência há algumas peças anatômicas completas de fetos humanos com anomalias, como microcefalia e malformação em feto possuindo duas cabeças; para comparação, a sequência se dá por peças anatômicas completas de fetos de animais, como um cadáver de porco com malformação facial, um casal de cadáveres de Codornas siamesas, um casal de cadáveres de Porcos siameses, um cadáver de Bezerro com oito patas, um cadáver de Ovelha com oito patas e um esqueleto completo de Bezerro com oito patas.

Em sequência temos peças anatômicas humanas em fase adulta, contanto também com uma peça anatômica de cadáver humano com variação anatômica de citus tottalis transversus, uma peça anatômica de cadáver humano montado artisticamente em posição sentada, duas peças anatômicos humanas inferiores dissecadas, feminina e masculina, para representar a variação anatômica entre os órgãos genitais e técnicas diferenciadas utilizadas no duas peças. Em sequência há uma bancada com peças anatômicas de ossos humanos com próteses, para demonstrar como a ela pode ser um recurso de auxilio durante a vida. Há uma montagem sequencial do processo digestivo contando com três peças anatômicas humanas de cabeças, onde é possível a visualização completa do membro, a vista longitudinal evidenciando a boca; há um tronco evidenciando o esôfago, separadamente há um estomago em sequência, com um fígado ao seu lado, dando continuidade um intestino delgado evidenciando seu comprimento, que causa espanto e muita curiosidade entre os visitantes devido ao comprimento, com um baço ao seu lado, dando continuidade um intestino grosso e uma pélvis masculina.

A UFG é uma das universidades do Brasil que possui um cadáver contendo uma rara variação anatômica o citus totallis transversus (uma variação em que todos os órgãos do corpo são invertidos em posicionamento). Muitas escolas trazem seus alunos para observar esta particularidade. Os alunos ficaram repletos de perguntas, curiosidades e admirados sobre esta variação anatômica. Há também a exposição de órgãos isolados como peças anatômicas de corações de animais e dois esqueletos completos humanos, sendo eles um feto e um adulto. $\mathrm{O}$ esqueleto de feto está montado e pendurado em uma caixa de 
vidro para exposição, o esqueleto de adulto está exposto sobre uma bancada em posição anatômica.

Os estudantes observaram também técnicas de preservação e montagem de peças anatômicas, como uma pata de cachorro mumificada, peça anatômica sintética de vascularização de uma pata de preguiça, ao ser explicado o processo de montagem desta peça os alunos demonstram bastante interesse, há outras peças anatômicas sintéticas de alvéolos pulmonares que passaram pela mesma técnica.

Ao fim da passagem da terceira sala foi utilizado um microscópio, da exposição do acervo de microscópios da UFG, para visualização de laminas histológicas de coração, devido a curiosidade dos visitantes, são doados fios de cabelo dos próprios visitantes para visualização microscopia dos mesmos, o que comumente gera discussões sobre o assunto, como o crescimento de cabelo e unhas após a morte.

Há modelos anatômicos sintéticos expostos no MM-UFG de tronco humano com órgãos e úteros em diferentes estágios de gestação.

A seguir são expostos os resultados que obtivemos ao longo do ano de 2017. Algumas escolas poderão ter sido atendidas em outros horários e podem não ter sido computadas. Entretanto apresentaremos os dados que obtivemos.

Para melhor compreensão dos dados separamos o ano de 2017 em dois semestres no qual o primeiro semestre abrange os meses de março a julho e o segundo semestre de agosto a dezembro. No primeiro semestre de 2017 foram recebidos no MM-UFG um total de seiscentos e três (603) visitantes, sendo duzentos e vinte e três (223) oriundos de escolas públicas de Goiânia e IF (Instituto Federal) e cento e oitenta e nove (189) de escolas particulares de Goiânia. Foram recebidos também oitenta e três (83) discentes de cursos de graduação da UFG como Biomedicina, ecologia, física médica e sessenta e oito (68) discentes dos cursos de Enfermagem e Ciências Biológicas de instituições de ensino superior. Além disso, quarenta (40) discentes do ensino técnico em radiologia de instituições particulares também foram recebidos (Gráfico 1). 
GRáFICO1- Número de estudantes atendidos no Museu de Morfologia da Morfologia da UFG no primeiro semestre de 2017.

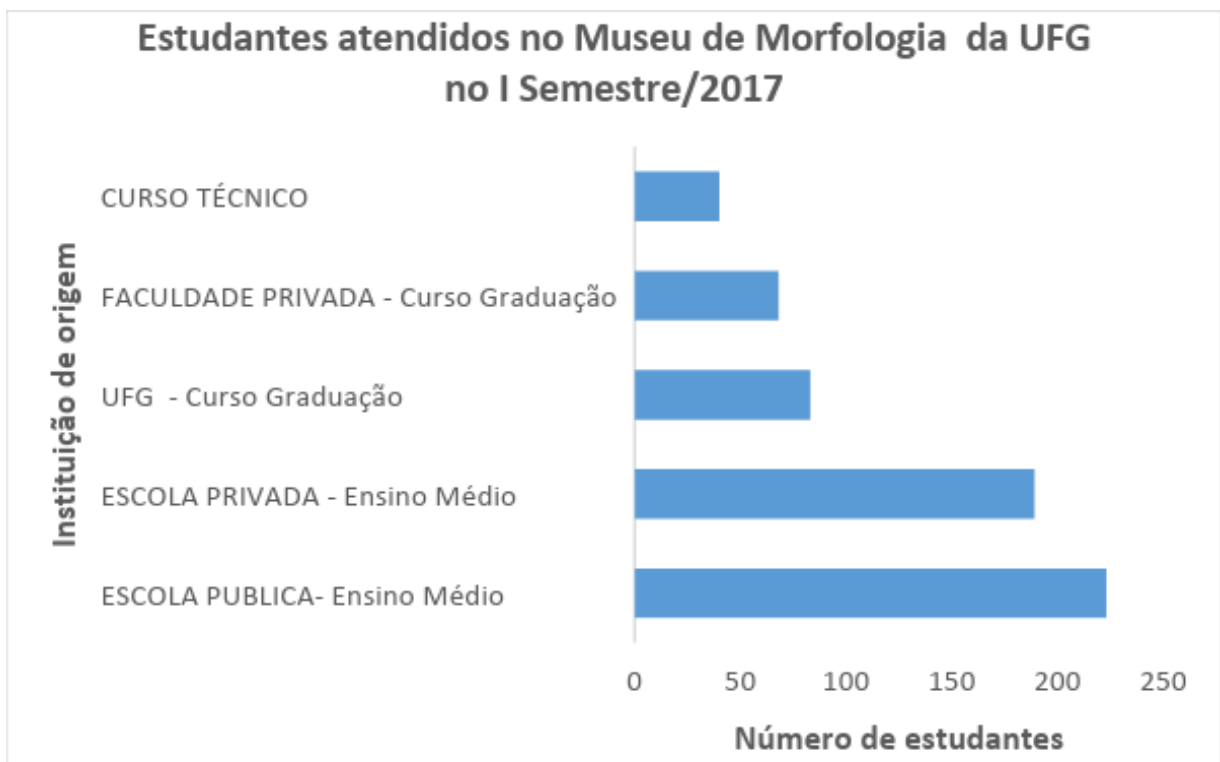

As instituições participantes foram: Colégio Protágoras (Goiânia - GO), CPMG Major Oscar Alvelos (Goiânia - GO), Faculdade Anhanguera (Goiânia - GO), Escola Estadual Juscelino Kubitschek de Oliveira (Goiânia - GO), Centro de Educação Profissional Irmã Dulce (Goiânia - GO), Colégio Estadual Dario Sampaio Paiva (Araguapaz - GO), Colégio Estadual Alto Paraiso (Aparecida de Goiânia - GO), Universidade Federal de Goiás (Goiânia - GO), Faculdade Araguaia (Goiânia - GO).

A tabela a seguir (Tabela 1) apresenta além do nome das instituições que visitaram o MM-UFG, o número de alunos que compareceram.

\begin{tabular}{|c|c|}
\hline INSTITUIÇÃOO & NÚMERO DE ALUNOS \\
\hline COLÉCIO PROTÁCORAS & 189 \\
\hline CPMC MAJOR OsCAR Alvelo & 102 \\
\hline FACULDADE ANHANGUERA & 52 \\
\hline ESCola EstaduAL JusCELINO KUBITSCHEK DE OLIVEIRA & 50 \\
\hline Centro de Educação Profissional Irmã DulCe & 40 \\
\hline ColÉcIo Estadual Dario Sampaio Paiva & 37 \\
\hline ColÉcio Estadual Alto Paraiso & 34 \\
\hline UNIVERSIDADE FEDERAL DE COIÁS & 83 \\
\hline FACULDADE ARAGUAIA & 16 \\
\hline TOTAL & 603 \\
\hline
\end{tabular}


No segundo semestre de 2017 foram recebidos no MM quatrocentos e onze (411) visitantes das seguintes instituições: Colégio Estadual Vila Boa (Goiânia - GO), IFG Campus Aparecida (Aparecida de Goiânia - GO), Colégio Estadual Costa e Silva (Aparecida de Goiânia - GO), Colégio Estadual Raimundo Santana Amaral (Rubiataba - GO), Colégio Estadual Heloisa de Fátima Vargas (Nova Glória - GO), Colégio Estadual Doutor Negreiros (Nerópolis - GO), Colégio Municipal Pedro Gomes de Menezes (Goiânia - GO), UEG (Iporá - GO); sendo trezentos e noventa (390) discentes oriundos de escolas públicas de Goiânia e IF (Instituto Federal), e vinte e um (21) discentes do curso de Ciências Biológicas da UEG (Universidade Estadual de Goiás), de Iporá (Gráfico 2).

GRÁrico 2- Número de estudantes atendidos no Museu de Morfologia da Morfologia da UFC no segundo semestre de 2017.

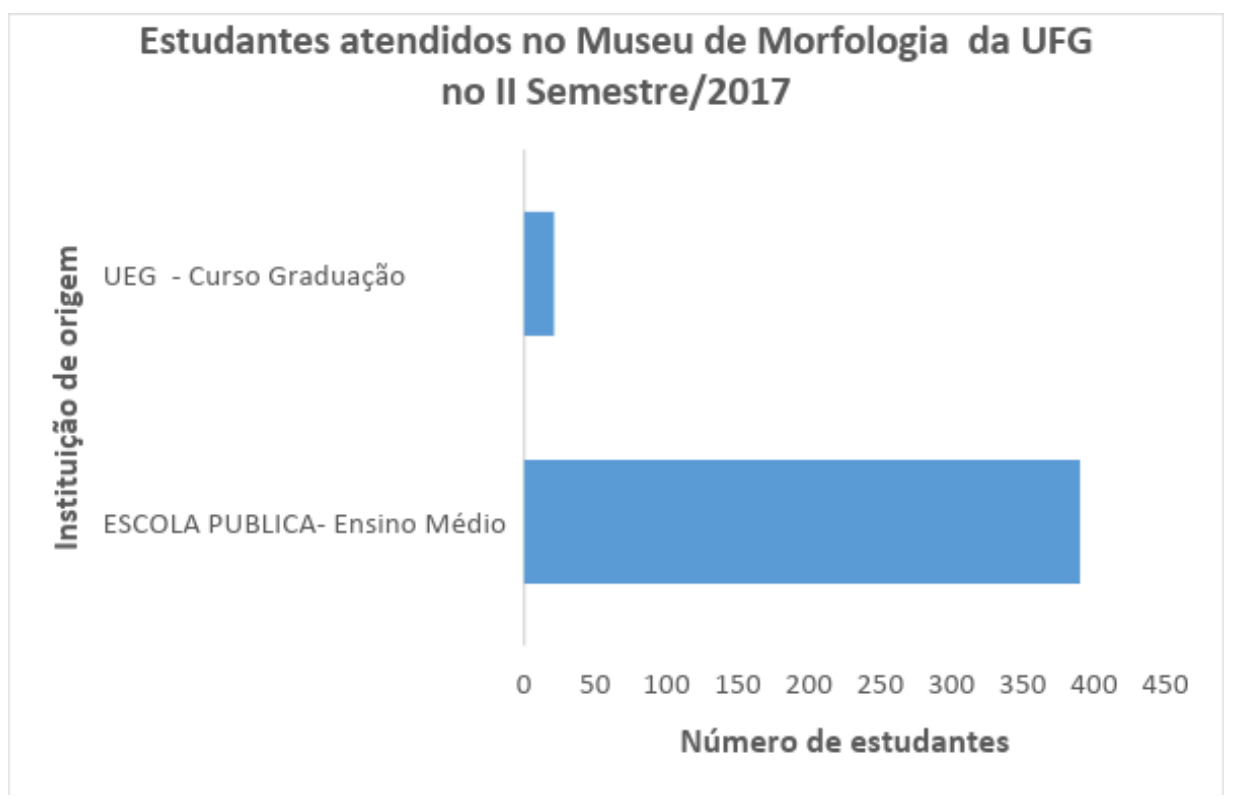

A tabela a seguir (Tabela 1) apresenta o nome das instituições que visitaram o MM-UFG seguido do número de alunos que compareceram. 


\begin{tabular}{|c|c|}
\hline INSTITUIÇÃO & NÚMERO DE ALUNOS \\
\hline Colécio Estadual Vila Boa & 126 \\
\hline IFG CAMPUS APARECIDA & 64 \\
\hline Colécio Estadual Costa e Silva & 37 \\
\hline ColÉCIO ESTAdUAL RAIMUNdo SANTANA AMARAL & 27 \\
\hline ColÉCio Estadual Heloisa de Fátima VARCAS & 33 \\
\hline ColÉcio Estadual DOUtor NEGreiros & 65 \\
\hline Colécio Municipal Pedro Gomes de Menezes & 38 \\
\hline UEG - CO IPORÁ & 21 \\
\hline TOTAL & 411 \\
\hline
\end{tabular}

Desta forma, no ano de 2017 o MM-UFG contou com um total de mil e quatorze (1.014), visitantes. Observou-se que o maior número discentes seiscentos e treze (613) foram oriundos de escolas públicas e IF’s. Isso demonstrou um determinado interesse de professores das redes de ensino públicas em aproximar os discentes a universidade, que às vezes é tida como uma possibilidade muito distante a realidade dos discentes. Tem sido muito discutido no meio acadêmico, tentativas de estabelecer parcerias e formas de aproximar os discentes do ensino médio a Universidade. Estudos mostram a importância de aproximar as pesquisas científicas das universidades e o ensino básico (Lüdke; Cruz, 2005). Além da importância de conhecer os percursos formativos e trilhas percorridas para atravessar o caminho incerto entre a escola pública e a universidade (SAMPAIO, 2011).

Neste contexto, as visitas do MM-UFG da Universidade buscaram envolver as escolas do Estado Goiás, principalmente da rede pública, desde as mais distantes da capital, até aquelas ao redor, de maneira a proporcionar o entendimento do estudante sobre o que é a Universidade, como são os cursos, como é o acesso, além de identificar e valorizar talentos, ampliando ainda mais o diálogo com estes jovens e atingi-los em grande escala. O menor número de discentes dos cursos de graduação da UFG mostrou que o MM-UFG ainda é desconhecido por grande parte dos estudantes e isso requer uma divulgação mais eficiente dentro da própria instituição.

No ano de 2016, o MM-UFG contou com oitocentos e quarenta (840) visitantes, das seguintes instituições: Escola Municipal Professora Silene de Andrade (Goiânia-GO), Escola Estadual Juscelino Kubitschek de Oliveira (Goiânia-GO), Colégio Protágoras (Goiânia-GO), Escola Municipal Prof ${ }^{a}$ 
Deushaydes Rodrigues de Oliveira (Goiânia-GO), Instituto Federal de Educação, Ciência e Tecnologia de Goiás - IFG (Goiânia-GO), Colégio Atlanta (Goiânia-GO), Educandário Espírita Eurípedes Barsanulfo (Goiânia - GO), Escola Estadual Juscelino Kubitschek de Oliveira (Goiânia - GO), Colegio Village Garavelo (Aparecida de Goiânia - GO), UEG (Iporá - GO), Colégio Estadual Olavo Bilac (Goiânia - GO); como também os cursos de: Biologia, Biomedicina, Educação Física, Musicoterapia, Psicologia, Medicina Veterinária, Nutrição e Enfermagem.

No ano de 2015, o MM-UFG contou com oitocentos e nove (809) visitantes, das seguintes instituições : Colégio Estadual Tomaz Martins da Cunha (Porangatu - GO), Escola Municipal Balneário Meia Ponte (Goiânia-GO), Escola Municipal Professora Dalisia Elizabeth Martins Dolles (Goiânia-GO), Instituto Federal Goiano - Campus Ceres (Ceres-GO), Colégio Estadual Alto Paraíso (Aparecida de Goiânia-GO), Colégio Vitória (Goiânia- GO), Colégio Estadual Presidente Costa e Silva (COLU) (Goiânia-GO) e Intepec Escola Profissionalizante (Goiânia-GO), bem como os graduandos de: Biologia, Biomedicina, Educação Física, Musicoterapia e Psicologia. Os dados totais de visitantes atendidos nos anos de 2015 a 2017 foram representados no gráfico-3.

GRáfICO 3- Número de estudantes atendidos no Museu de Morfologia da Morfologia da UFG nos anos de 2015, 2016 e 2017.

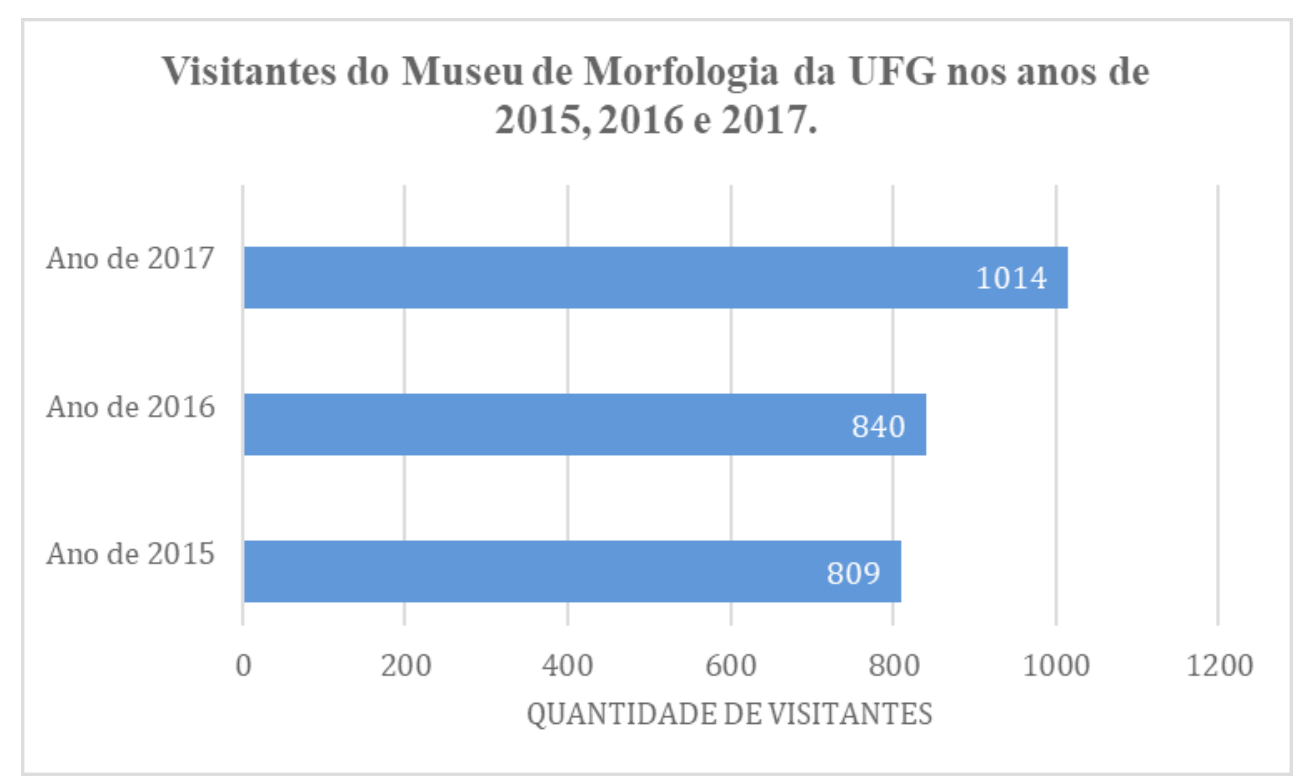


Em comparação ao ano de 2015 até o fim do ano de 2017 houve um aumento total de $25,33 \%$, de visitantes no MM-UFG, sendo 3,83\% de aumento do ano de 2015 ao ano de 2016 e 20,71\% de aumento do ano de 2016 ao ano de 2017.

O aumento do percentual de visitantes, pode se dar a divulgação cientifica, explicação do termo: “Também denominada vulgarização ou popularização da ciência, a divulgação cientifica constitui-se no emprego de técnicas de recodificação de linguagem da informação cientifica e tecnológica objetivando atingir o público em geral e utilizando diferentes meios de comunicação de massa." (BRASIL, 1999), como cita Brasil, a divulgação cientifica é um fator auxiliador não só no aumento de visitantes, mas também um dispersar de conhecimentos entre os cidadãos.

Tendo em vista o avanço tecnológico e a grande utilização de mídias sociais, uma divulgação intensa nessas mídias relacionadas a UFG, possivelmente pode ser um fator auxiliador na divulgação cientifica do MM, alcançando os estudantes da própria instituição, como professores e discentes de outras instituições, que não estão cientes da existência do MM-UFG ou de sem funcionamento ativo, podendo também alcançar moradores da região e funcionários terceirizados da UFG.

Desta forma, o MM-UFG tem atuado com um importante papel no processo ensino-aprendizagem para os discentes do ensino fundamental e médio oportunizando o contato prático com peças anatômicas humanas e animais para a ampliação do conhecimento sobre o corpo humano e animal buscando tirar as dúvidas e questionamentos gerados sobre as diversas áreas de Ciências Biológicas e da Saúde sendo estimulado o interesse dos mesmos pelas áreas acadêmicas na UFG.

\section{Conclusão}

A partir deste estudo conclui-se que o MM-UFG é um importante espaço de divulgação, difusão e crescimento no conhecimento dos visitantes acerca da Morfologia. A oportunidade de contato prático com as peças anatômicas do acervo desperta o interesse dos estudantes durante a visita em aprender mais sobre o corpo humano e animal contribuindo na ampliação e sedimentação do conhecimento teórico adquirido na sua escola facilitando o processo ensino-aprendizagem. O MM-UFG também se tornou um lugar de extensão 
do conhecimento produzido dentro da universidade, pois é aberto ao público de fora da Universidade.

Além de contribuir na construção ética e moral dos visitantes, uma vez que neste espaço foi destacada a formação humana atrelada ao conhecimento anatômico seja animal ou humano. É um espaço que ainda necessita de ampla divulgação dentro da própria universidade em busca de aumentar a quantidade de visitas dos discentes da própria UFG.

\section{REFERÊNCIAS}

ALMEIDA, A.M. O contexto do visitante na experiência museal: semelhanças e diferenças entre museus de ciências e arte. História e Ciências da Saúde Manguinho. 12: 31-53, 2005.

BRANDÃO, Carlos R. O que é educação. São Paulo, Brasiliense, 1981.

BRASIL (1999). Diretrizes curriculares nacionais para o ensino médio. Parâmetros curriculares nacional - Ensino Médio, Vol. 1. Brasilia: Ministério da Educação, Secretaria da Educação Média e Tecnológica.

De SOUZA, N.B.; MATA, J.R.; OLIVEIRA, K.M.; NOGUEIRA, D.J.; FERREIRA, J.R. . Extensão ou assistencialismo? Arena e atores dos programas institucionais de extensão em anatomia na Universidade Federal de Goiás. Arquivos da Apadec, Maringá, 5: 40-46, 2001.

FERREIRA, JR; LUIZ, CR; MATA, JR; MIRANDA, DF; CARNEIRO, LB. O papel Educativo do Museu Didático. Arq. Ciênc. Saúde Unipar, 3: 231-137, 1999.

GUZZO Marcelo Moraes. Educar pela pesquisa e os museus de Ciências: um estudo de caso na Nanoaventura.2006.

LIBÂNEO, José Carlos. Pedagogia e pedagogos, para quê? 12a ed. São Paulo: Cortez, 2010.

LEÃO, Mateus Queiroz Freire; MACIEL; Raquel Aragão; NETO, Leonel Azevedo da Silva;

LOUREIRO, José Mauro Matheus. Museu de ciência, divulgação científica e hegemonia. fulano, Brasília, 1: 88-95, 2003.

OLIVEIRA, Jaciel Benedito de; ARAÚJO, Fábio Andrey da Costa; FILHO, Eduardo Sérgio Donato Duarte. Projeto de monitoria "anatomia ao vivo": Um trabalho que transcende as portas da Universidade. Leão MQF et al. Revista Saúde e Ciência online, 2015; 4(3): 07-20.

LOZADA, Cláudia de Oliveira; ARAÚJO, Mauro Sérgio Teixeira de, Marcelo Moraes PROEC. Relatório das atividades de extensão desenvolvidas pela UFG no período de 1994 a 1997. Revista de Extensão Universitária, 1: 16-18, 1997a. 
ROLDAO, M. C. Função docente: natureza e construção do conhecimento profissional. Rev. Bras. Educ. 12: 94-103, 2007.

STUDART D.C. Museus e famílias: percepções e comportamento de crianças e seus familiares em exposição para o público infantil. História e Ciências da Saúde Manguinho. 12: 55-77, 2005.

VALENTE, M.E.; CAZELLI S, A.F. Museus, ciência e educação: novos desafios. História e Ciências da Saúde Manguinho. 12: 183-203, 2005.

VIEIRA, Valéria; BIANCONI, M. Lucia; DIAS, Monique. Espaços não-formais de ensino e o currículo de ciências. Ciência e Cultura, v. 57, n. 4, p. 21-23, 2005. 